\title{
Comparison of three isotopic methods for the study of calcium absorption
}

\author{
J. E. AGNEW, A. K. KEHAYOGLOU, ${ }^{1}$ AND C. D. HOLDSWORTH ${ }^{2}$ \\ From the Departments of Medical Physics and Medicine Royal Free Hospital, London
}

Until recent years it has been possible to study calcium absorption in man only by using metabolic balance techniques. These demand a meticulous technique which limits their application to patients confined to a metabolic ward. Early radioactive tracer studies used the beta-emitting isotope ${ }^{45} \mathrm{Ca}$ (Blau, Spencer, Swernov, Greenberg, and Laszlo, 1957) but use of this isotope is limited by its long half-life of 165 days. The gamma-emitting isotope ${ }^{47} \mathrm{Ca}$, now freely available, is more suitable for human studies. Its short half-life of $\mathbf{4 \cdot 7}$ days reduces the radiation hazard and facilitates the performance of repeated studies. It can be estimated in plasma, stools, or urine without any need for prior handling or chemical manipulation of the specimens, and the amount in the body can be determined with a wholebody counter.

Of the several methods which have been used to assess ${ }^{47} \mathrm{Ca}$ absorption, the determination of plasma radioactivity one or two hours after oral administration of the isotope is the simplest, although most liable to influence by factors other than absorption. Avioli, McDonald, Singer, and Henneman (1965) reported a good correlation between the plasma radioactivity measurement at one hour and absorption of the isotope as determined from faecal radioactivity measurements. On the other hand, Jaworski, Brown, Fedoruk, and Seitz (1963) and Kinney, Tauxe, and Dearing (1965) found little or no correlation between plasma ${ }^{47} \mathrm{Ca}$ levels and ${ }^{47} \mathrm{Ca}$ absorption. In this paper the value of plasma ${ }^{47} \mathrm{Ca}$ levels as an indication of ${ }^{47} \mathrm{Ca}$ absorption has been reassessed by comparing results obtained using this method with those obtained in the same subjects by the use of a simple whole-body counter. In addition the validity of the whole-body counting method was assessed by comparing the results with those obtained by measuring faecal radioactivity.

'Present address: Therapeutic Clinic of Athens University, Alexandria Hospital, Athens, Greece.

${ }^{2}$ Present address: Dunn Laboratories, Department of Medicine, St Bartholomew's Hospital, London E.C.1.

\section{METHODS}

PATIENTS STUDIED Sixty-three inpatients were studied while on a general medical ward. Nineteen had no evidence of gastrointestinal or bone disease and 44 had some condition which might affect calcium absorption. Of these 13 were patients with primary biliary cirrhosis, and seven had gluten-sensitive enteropathy. There were also individual cases of idiopathic hypercalciuria, multiple myeloma, and postnecrotic cirrhosis. Clinical details of many of these patients have been given elsewhere (Kehayoglou, Agnew, Holdsworth, Whelton, and Sherlock, 1968). The diet before admission to the ward was assessed by dietary survey: the calcium content varied widely from 357 to $2,580 \mathrm{mg}$ daily and the vitamin D content from 35 to 2,500 IU daily. Most patients were studied once only but 17 were retested four to 12 weeks after intramuscular vitamin D (Calciferol) had been given according to the regime $100,000 \mathrm{IU}$ weekly for four doses, followed by 100,000 IU monthly.

PROCEDURE After an overnight fast, $10 \mu \mathrm{Ci}$ of ${ }^{47} \mathrm{CaCl}_{2}$ dissolved in distilled water with $10 \mathrm{mg}$ of 'carrier' calcium as $\mathrm{CaCl}_{2}$ was administered through a drinking straw. Venous blood for radioactivity measurements was taken one, two, three, 24 , and 168 hours after the dose was given. For the initial studies in which the performance of the whole-body counter was evaluated, whole-body radioactivity was measured before the dose, at five minutes, half, one, two, three, and five hours after the dose, and then daily for seven days. Separate 24-hour collections of urine and stools for radioactivity measurements were made daily for seven days; all specimens were subsequently counted in the containers into which they were initially collected.

In each of the initial studies performed for evaluation of the whole-body counter, the daily change in the patient's whole-body count rate was compared with the daily excretion of ${ }^{47} \mathrm{Ca}$ in the stools and urine. If in any 24-hour period there was a large fall in the whole-body count rate but only a small percentage of the ${ }^{47} \mathrm{Ca}$ dose appeared in the stool and urine collections, this indicated that a stool collection had been omitted. Data from any patient were also rejected if the amounts of stools and urine received in the laboratory did not tally exactly with the stool and urine charts kept in the ward. The 
application of these criteria for complete collection led to the rejection of data from 12 out of 52 studies which might otherwise have been used in the construction of Table I and Figure 2.

In the later studies the procedure was simplified. The stool collections were omitted and whole-body radioactivity was measured only before the dose, three hours after the dose, and seven days later.

A!l patients were allowed to eat three hours after receiving the ${ }^{47} \mathrm{Ca}$ and then took a normal diet, although some were given a low calcium diet for the last four days of the test so that a calcium infusion test could be performed on the sixth and seventh days, using the method of Nordin and Fraser (1956). In our hands the normal lower limit is an excretion of $22 \%$ of the infused dose. An excretion of less than $22 \%$ indicates increased avidity of the body for infused calcium, and is consistent with osteomalacia.

RADIOACTIVITY MEASUREMENTS Whole-body counting was performed with the single crystal whole-body counter of the Royal Free Hospital. Gamma radiation from the seated patient is detected by a 5 in. diameter crystal of thallium-activated sodium iodide mounted in a 'local' shield of low radioactivity lead to reduce the background falling upon it. A single channel pulse height analyser is used to select counts in an energy band 1.15 to $1.45 \mathrm{Mev}$, containing the $1 \cdot 31 \mathrm{Mev}$ gamma radiation from ${ }^{47} \mathrm{Ca}$.

Plasma samples, each of $3 \mathrm{ml}$, were measured in a Packard Auto-Gamma spectrometer (type 5213) set to count only the $1.31 \mathrm{Mev}{ }^{47} \mathrm{Ca}$ gamma radiation. The ${ }^{47} \mathrm{Ca}$ content of the stool and urine collections was measured with a cylindrical array of six G26Pb Geiger tubes in a lead castle (Veall and Vetter, 1952), a $2 \mathrm{~mm}$ thick lead screen being placed around the specimen to screen out radiation from ${ }^{47} \mathrm{Sc}$, the radioactive daughter product of ${ }^{47} \mathrm{Ca}$. The counts from the urine containers were corrected for the variation of counting efficiency with sample volume. Because of their much smaller volume, no such correction was needed for the stool specimens. The maximum error due to not homogenizing the stools was estimated by experiment to be less than $2 \%$.

CALCULATION OF ABSORPTION Any absorbed ${ }^{47} \mathrm{Ca}$ resecreted into the bowel and not subsequently reabsorbed is treated as not absorbed. Our experience in other studies using ${ }^{51} \mathrm{Cr}$ salts as non-absorbable markers has shown that in patients who are not obviously constipated all unabsorbed materials are excreted from the bowel in less than seven days. Accordingly absorption may be estimated from the ${ }^{47} \mathrm{Ca}$ activity in a complete seven-day stool collection

$\%$ Absorption $\left(\mathrm{A}_{\mathrm{ex}}\right)=\frac{{ }^{47} \mathrm{Ca} \text { dose }-{ }^{47} \mathrm{Ca} \text { in stools }}{{ }^{47} \mathrm{Ca} \text { dose }} \times 100$

Using the whole-body counter, the percentage retention may be obtained directly by comparing the whole-body count rate after seven days (corrected for radioactive decay) with an initial value measured before any ${ }^{47} \mathrm{Ca}$ is excreted.

$$
\begin{aligned}
& \% \text { Retention }(\mathrm{R}) \\
& =\frac{\text { whole-body count rate after seven days }}{\text { initial whole-body count rate }} \times 100 \\
& \text { RESULTS }
\end{aligned}
$$

COMPARISON OF WHOLE-BODY AND EXCRETA COUNTING Measuring the retention of any radioisotope by whole-body counting is complicated by the fact that, even before any excretion occurs, the count rate fluctuates as the distribution of radioisotope in the body alters. A single crystal whole-body counter is particularly sensitive to such alterations; in fact in a few tests changes in count rate as great as $30 \%$ during the first five hours were observed. There is thus no single 'initial' count on which the whole-body counter retention estimate $(R)$ can be based. Six different times (five min, half, one, two, three, and five hours after dose) were therefore tried for the initial whole-body count. Table I shows the correlation between retention by stool and urine counting $\left(R_{e x}\right)$ and the whole-body counter retention estimates obtained with each in turn of the six initial count times. This comparison is based on 40 studies performed on 29 patients and normal controls covering a wide retention range. The three-hour initial count was found to give the highest correlation coefficient ( $\mathrm{r}=0.93, \mathrm{P}<0.001)$. Using a method due to Barrett (1967), approximate values of the standard errors of the differences between this value and each of the other correlation coefficients for the correlation between $R$ and $R_{\text {ex }}$ (Table I) were calculated so that the significance of the differences could be assessed by the $t$ test. The difference was found to be significant $(P<0.05)$ only in the case of the one-hour initial count. The regression of the whole-body counter retention estimate obtained with the three-hour initial reading $\left(R_{3} h r\right)$ on $R_{e x}$ is illustrated in Figure 1.

\section{TABLE I}

CORRELATION BETWEEN THE RESULTS OF WHOLE-BODY AND EXCRETA COUNTING

Time of Initial Whole-body Count

\begin{tabular}{lcccccc}
\cline { 2 - 5 } Correlation & $5 \min$ & $\frac{1}{2} h r$ & $1 \mathrm{hr}$ & $2 \mathrm{hr}$ & $3 \mathrm{hr}$ & $5 \mathrm{hr}$ \\
\hline $\begin{array}{l}\text { r for correlation } \\
\text { between R and R ex }\end{array}$ & 0.88 & 0.90 & 0.87 & 0.90 & 0.93 & 0.91 \\
$\begin{array}{l}\text { r for correlation } \\
\text { between R and A }\end{array}$ & 0.85 & 0.87 & 0.81 & 0.86 & 0.87 & 0.85
\end{tabular}

However, as it is generally absorption rather than retention which is of interest, the correlation between $\mathrm{R}$ and $\mathrm{A}_{\text {ex }}$ was also determined for the same $\mathbf{4 0}$ studies (Table I). The correlation coefficients are now a little lower, reflecting the variability in the proportion of the absorbed ${ }^{47} \mathrm{Ca}$ appearing in the 


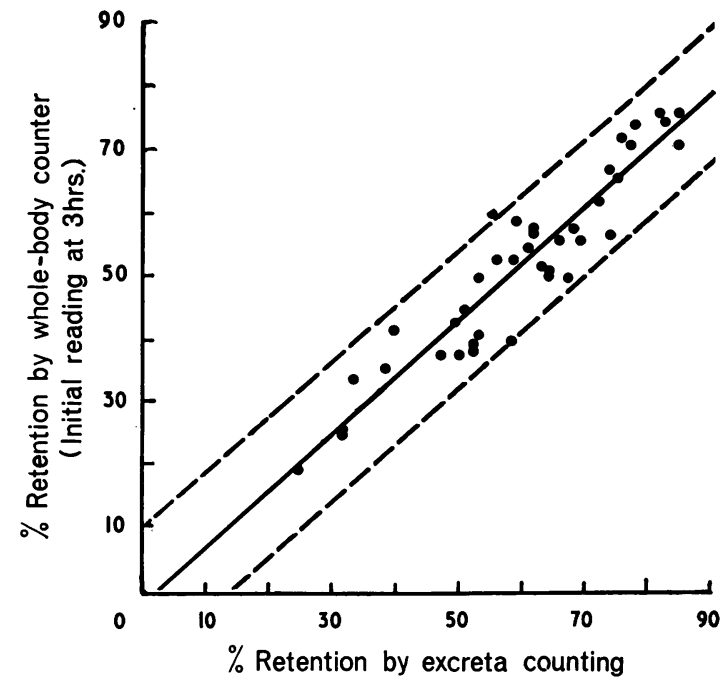

FIG. 1 .

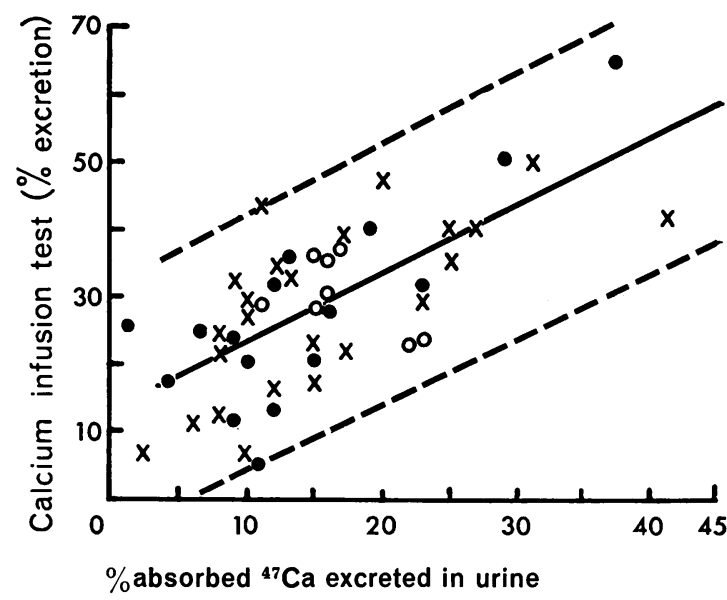

FIG. 2.

FIG. 1. Correlation between retention measured by whole-body counting and retention estimated by measuring radioactivity excreted in stools and urine.

Unbroken line $=$ regression of $\mathbf{R}_{3} \mathrm{hr}$ on $\mathbf{R}_{\mathrm{ex}} ;$ broken line $=95 \%$ confidence limits for $\mathbf{R}_{3} \mathrm{hr}(n=40, r=0.93, P$ $<0.001$ ).

FIG. 2. Relationship between result of calcium infusion test and proportion of absorbed ${ }^{47} \mathrm{Ca}$ excreted in the urine in seven days.

Unbroken line $=$ regression line; broken line $=95 \%$ confidence limits for excretion in infusion test; $\bigcirc=$ control subjects; $\times=$ primary biliary cirrhosis; $O=$ all other patients $(n=47, r=0.69, P<0.01)$.

urine within seven days, but they are still highly significant $(\mathrm{P}<0.001)$.

The seven-day urinary output of ${ }^{47} \mathrm{Ca}$ was measured in 65 studies. In 11 control subjects the mean output was $10 \pm 8 \%$ of the dose (mean \pm 2 SD). Of 54 studies on patients with various abnormal conditions, 52 gave seven-day urinary outputs between 1 and $19 \%$. The two remaining cases (one a patient with primary biliary cirrhosis who had received eight weeks of vitamin $D$ treatment, the other a patient with idiopathic hypercalciuria) both excreted approximately $30 \%$ of the dose in the urine. These two patients excreted $11 \%$ and $8 \%$ (respectively) of the dose in the urine during the first 24 hours, whereas no other patient excreted more than $5 \%$ in the urine during the same period. It is therefore possible to exclude the rare patient whose urinary calcium is sufficiently high to invalidate assessment of absorption by a whole-body counting method by measuring urinary ${ }^{47} \mathrm{Ca}$ excretion for the first 24 hours after the oral dose. There was no significant correlation between the seven-day urinary output of ${ }^{47} \mathrm{Ca}$ and the retention of the isotope. On the other hand, as shown in Fig. 2, a significant correlation was found between the proportion of the absorbed ${ }^{47} \mathrm{Ca}$ excreted in the urine and the result of the calcium infusion test (expressed as the percentage urinary excretion of the infused calcium).

The good correlation $(\mathrm{r}=0.87, \quad \mathrm{P}<0.001$, $\mathrm{n}=40$ ) observed between retention measured by whole-body counting (using an initial count at three hours) and absorption determined from faecal radioactivity shows that the retention figure is satisfactory for use as an estimate of ${ }^{47} \mathrm{Ca}$ absorption. High urinary ${ }^{47} \mathrm{Ca}$ excretion is only rarely sufficient to invalidate the result obtained, and is easily detected by one urine collection.

RETENTION RANGE IN NORMAL AND ABNORMAL SUBJECTS (FIG. 3) Mean retention by whole-body counting for the 19 controls studied was $49 \%$ with a range of 36 to $62 \%$ (mean \pm 2 SD). No significant variation could be detected with either the age, sex, or previous calcium intake of the patient. Of the 13 patients with untreated primary biliary cirrhosis, four with substantially raised faecal fat and serum bilirubin levels had subnormal retention. Two patients with normal faecal fat and serum bilirubin levels retained rather more than the control subjects. All 


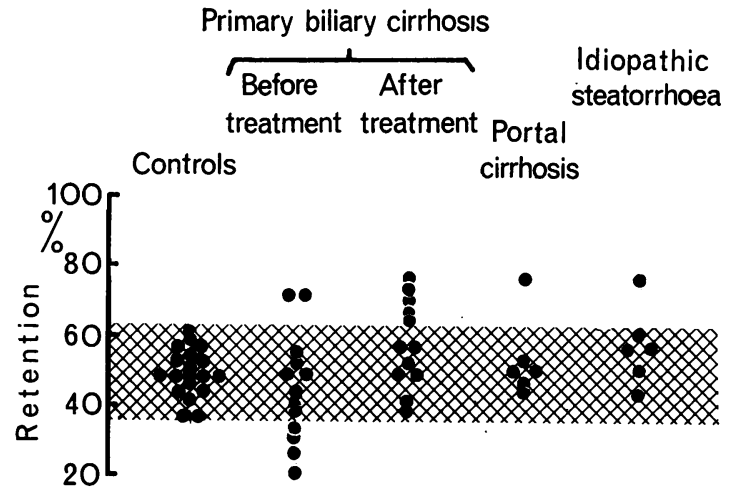

FIG. 3. Retention of ${ }^{47} \mathrm{Ca}$ by whole-body counting $(R)$. The shaded area is the normal range (mean $\pm 2 S D)$.

patients treated with vitamin $\mathrm{D}$ gave normal or high retention values.

The six patients with idiopathic steatorrhoea included patients both before and during treatment with a gluten-free diet. None had overt osteomalacia, although the calcium infusion test was abnormal in each of the four in whom it was performed. Subnormal retention was found in four patients whose results are not shown in Figure 3. Of these, one patient with osteomalacia and gross pancreatic steatorrhoea had a retention of only $26 \%$ rising to $82 \%$ after vitamin D treatment. Subnormal retention was found in one case of chronic intrahepatic obstructive jaundice due to chlorpromazine $(25 \%)$,

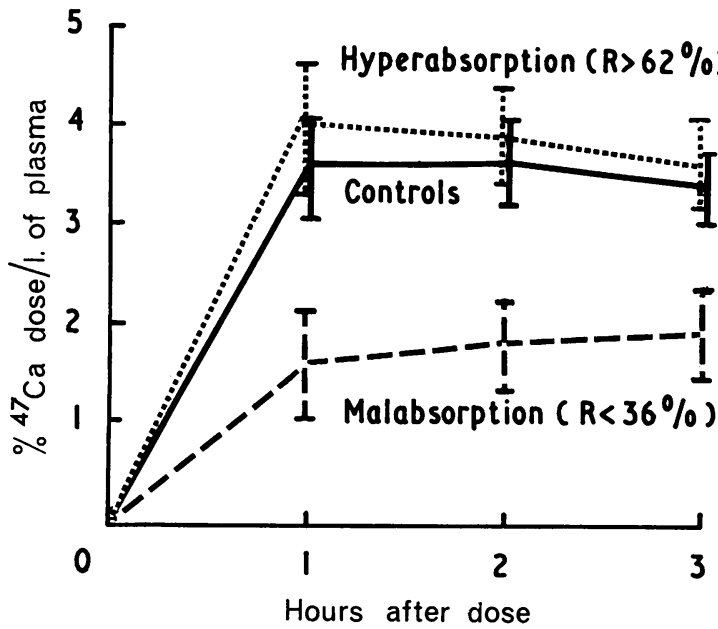

FIG. 4. Variation of plasma radioactivity with time in 19 controls, 13 patients with $R>62 \%$ (mean retention $74 \%, S D 7 \%$ ), and 11 patients with $R<36 \%$ (mean retention $27 \%, S D 5 \%$ ). Vertical lines indicate mean $\pm 2 S E$. one of chronic extrahepatic obstructive jaundice $(21 \%)$, and one of acute extrahepatic obstructive jaundice ( $35 \%)$.

A high retention ( $81 \%)$ was found in one patient who had been given 50,000 units daily of Calciferol for one year and presented with hypercalcaemia. After two months without Calciferol the patient was retested and found to have a normal retention $(45 \%)$.

WHOLE-BODY AND PLASMA COUNTING COMPARED After the whole-body counting method had been established by comparing it with excreta counting, the stool collections were omitted in subsequent tests. The validity of plasma ${ }^{47} \mathrm{Ca}$ levels as an index of calcium absorption was tested by comparing them with the whole-body retention measurements.

Variation of plasma radioactivity with time (Fig. 4) No significant difference in plasma radioactivity at one, two, or three hours was found between the controls and the patients with greater than normal retention. On the other hand, at each time of measurement the mean value obtained from the patients with subnormal retention was significantly lower than that from the controls $(P<0.001)$.

The significance of changes in plasma radioactivity in each group with time was assessed by paired $t$ tests. The control and hyperretaining groups showed no significant change during the second hour but a significant fall during the third hour $(P<0.01)$. The group with subnormal retention showed a significant rise during the second hour $(P<0.05)$ but not during the third. These patients cannot, however, be held to constitute a representative group of malabsorptive states. They include four cases of primary biliary cirrhosis and three of cholestatic jaundice. Five of these seven patients had higher plasma ${ }^{47} \mathrm{Ca}$ values at three hours than at one or two hours. A prolonged rise in plasma radioactivity seems to be a common feature in biliary obstruction, even when calcium absorption is normal. All seven of the primary biliary cirrhosis patients whose retention lies within the normal range (Fig. 3) showed at least a small increase in plasma radioactivity during the third hour, an increase shown to be significant by the paired $t$ test $(P<0.05)$.

Correlation between retention and plasma ${ }^{47} \mathrm{Ca}$ concentration (Figs. 5 and 6) Although the scatter of individual points is wide, there is a significant correlation between retention and the one- and three-hour plasma ${ }^{47} \mathrm{Ca}$ levels $(r=0.53$ and 0.55 respectively, $\mathrm{P}<0.01, \mathrm{n}=89$ ). A similar correlation was observed between retention and the twohour plasma level $(\mathrm{r}=0.54, \mathrm{P}<0.01, \mathrm{n}=89)$. No significant correlation was found between retention and the plasma levels at 24 hours and seven days. The 


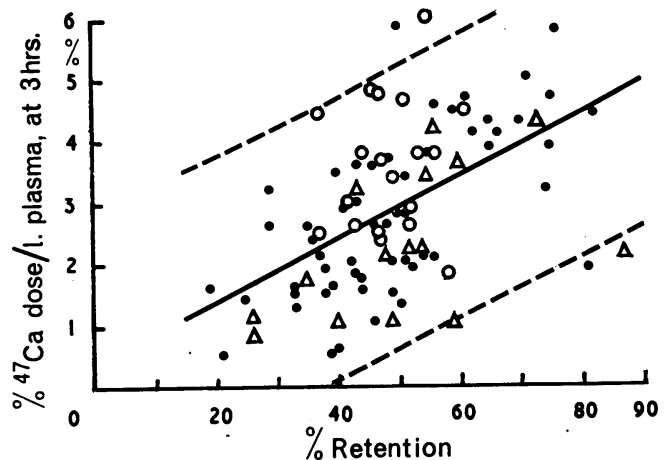

FIG 5. Relationship between plasma ${ }^{47} \mathrm{Ca}$ one hour after dose and retention by whole-body counting ( $n=89, r=$ $0.53, P<0.01)$.

Unbroken line $=$ regression line for all tests

Broken line $=95 \%$ confidence limits for plasma ${ }^{17} \mathrm{Ca}$ concentration.

$\mathrm{O}=$ control subjects

$\triangle=$ patients with abnormal calcium infusion test results

$=$ all other patients.

difference between the slopes of the regression lines in Figs. 5 and 6 is significant $(P<0.05)$ and arises from the tendency of patients with low retention to give higher plasma levels at three hours than at one hour, and of patients with higher retention to give lower levels at three hours.

Low plasma ${ }^{47} \mathrm{Ca}$ levels may represent a large exchangeable pool of stable calcium in addition to defective absorption. Therefore the 15 patients whose calcium infusion test results suggested osteomalacia and hence a large exchangeable pool (Fraser, Harrison, and Ibbertson, 1960) were plotted in Figs. 5 and 6 with different symbols. The mean retention of these 15 patients $(51 \%)$ is almost identical to that of the controls $(49 \%)$ but their mean one-hour plasma ${ }^{47} \mathrm{Ca}$ level is significantly reduced $(\mathrm{P}<0.01)$.

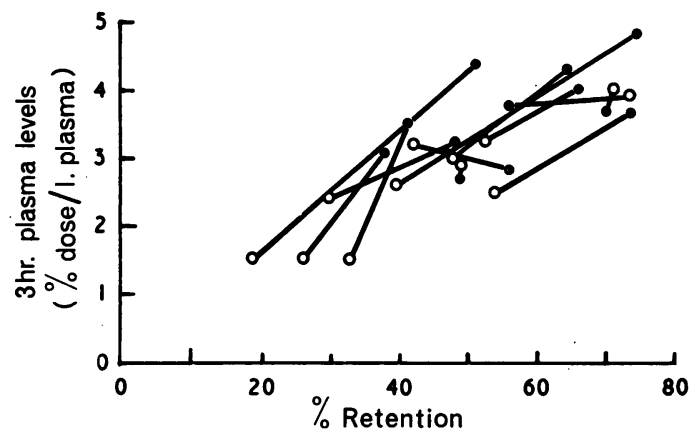

FIG. 7. Effect of vitamin $D$ on retention and three-hour plasma ${ }^{47} \mathrm{Ca}$ in primary biliary cirrhosis.

$\bigcirc=$ before vitamin $D$

= after vitamin $D$

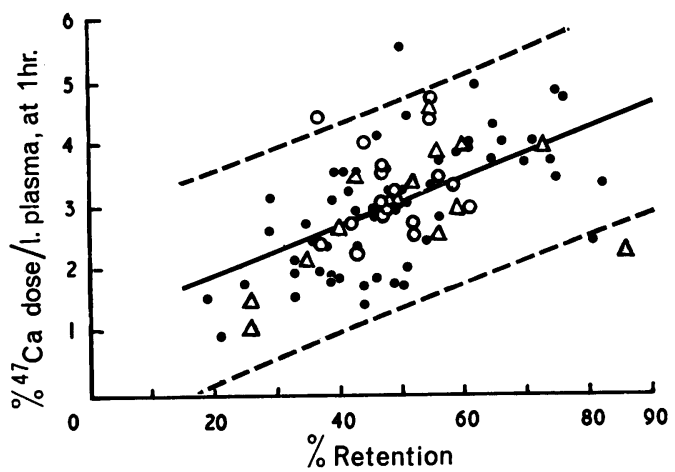

FIG. 6. Relationship between plasma ${ }^{47} \mathrm{Ca}$ three hours after dose and retention by whole-body counting $(n=89$, $r=0.55, P<0.01)$.

Unbroken line $=$ regression line for all tests

Broken line $=95 \%$ confidence limits for plasma ${ }^{47} \mathrm{Ca}$ concentration

$\bigcirc=$ control subjects

$\Delta=$ patients with abnormal calcium infusion test results.

$=$ all other patients

Ten of the 15 (including six cases of primary biliary cirrhosis) lie below the regression line in Figure 5. Results for all four patients with idiopathic steatorrhoea and an abnormal infusion test lie above the line.

At two and three hours, on the other hand, there is no significant difference between the mean plasma levels of the patients giving abnormal infusion test results and those of the control group. These patients' results are much more evenly distributed about the regression line of the three-hour plasma ${ }^{47} \mathrm{Ca}$ concentration on retention (Fig. 6). It should be pointed out that calcium infusion tests were not performed on all the subjects whose results are depicted in Figs. 5 and 6 and that some of the other patients, represented by closed circles, may also have had osteomalacia.

Effect of vitamin D treatment Twelve patients with primary biliary cirrhosis were re-tested after six to 12 weeks of vitamin D treatment. The changes in retention and the three-hour plasma ${ }^{47} \mathrm{Ca}$ level are shown in Figure 7. The fractional increase in three-hour plasma radioactivity (ie, the ratio of the increase in plasma radioactivity to its value before treatment) correlated well with the fractional increase in retention $(\mathrm{r}=0.78, \mathrm{P}<0.01, \mathrm{n}=12)$. The correlation was less good in the case of the oneand two-hour plasma levels $(r=0.70$ and 0.63 respectively, $\mathrm{P}<0.05, \mathrm{n}=12$ ).

\section{DISCUSSION}

The study of calcium absorption by the calciumbalance technique is subject to considerable errors 
due to the fact that most calcium is excreted by the faecal route. Particularly when absorption is poor, small errors in the collection or measurement of faecal calcium can invalidate the result, although these can be minimized by using a non-absorbable marker (Rose, 1965). Balance techniques only measure 'net' absorption, but as secreted calcium is relatively constant (Cramer, 1963) and small (De Grazia and Rich, 1964), this is usually satisfactory, although large and often incomprehensible fluctuations do occur (Badenoch and Fourman, 1954). The absorption of isotopic calcium probably reflects 'true' rather than 'net' absorption, since in normal subjects only a small fraction of an intravenous dose of isotopic calcium is excreted in the stools (Bronner, Harris, Maletskos, and Benda, 1956). In vitamin-D-deficient subjects there is evidence that calcium excreted into the intestine is not reabsorbed normally (Hunt, Garcia, Hegsted, and Kaplinsky, 1967), and this may lead to a larger endogenous pool of calcium within the intestinal lumen which will mix with the orally administered isotopic dose. As the percentage calcium absorption decreases with increasing size of administered load (Rich and Ivanovitch, 1964), an increase of endogenous calcium loss could lead to apparent depression of 'true' absorption. If this is the case, then no type of isotope method can give an actual estimate of 'true' absorption. In practice, however, it is reassuring that the correlation between an isotopic method and a carefully conducted calcium balance is quite good (Rose, Reed, and Smith, 1965).

${ }^{47} \mathrm{Ca}$ decays with a half-life of 4.7 days to a radioactive daughter product ${ }^{47} \mathrm{Sc}$ (half-life 3.45 days) which emits both beta and gamma radiation. Commercially available ${ }^{47} \mathrm{Ca}$ usually contains up to $10 \%$ of the beta-emitting isotope ${ }^{45} \mathrm{Ca}$. The wholebody radiation dose to the patient from an oral dose of $10 \mu \mathrm{Ci}{ }^{47} \mathrm{Ca}$, including the contributions from ${ }^{47} \mathrm{Sc}$ and ${ }^{45} \mathrm{Ca}$, is less than $0 \cdot 2 \mathrm{rad}$ (Deller, Worthley, and Martin, 1965), ie, very much less than that arising from many diagnostic radiographic procedures. Although the short life of ${ }^{47} \mathrm{Ca}$ precludes its use for long-term metabolic studies, it is ideally suited for absorption studies which can be repeated after a few weeks without the need to allow for any radioactivity remaining from the previous test, and with a radiation dosage well within permissible limits.

A small carrier dose of calcium not mixed with food was chosen for these studies for two reasons. First, absorption and retention would be high, thus facilitating whole-body counting with a simple and relatively insensitive instrument, although subsequent experience has in fact shown that the instrument is quite capable of measuring the smaller percentage retention which occurs if the dose is mixed with milk. Secondly, it has been claimed when using a small carrier dose that plasma ${ }^{47} \mathrm{Ca}$ levels one hour after oral administration may be used as a reliable index of calcium absorption in man (Avioli et al, 1965). It is not claimed that the method described in this paper will necessarily reflect dietary calcium absorption, for there are many substances in a normal mixed meal which are capable of depressing or stimulating calcium absorption. This test can, however, be used to provide useful physiological information, eg, response to vitamin therapy in vitamin-D-deficient patients, which might be masked if the dose is mixed with food.

Isotopic calcium absorption can be studied most simply by measuring the cumulative faecal excretion over several days, until all unabsorbed calcium has been passed. Unless some method is used to check for complete stool collections, large errors can occur, and these probably account for the relatively poor correlation with whole-body counting which has sometimes been observed (Deller et al, 1965). All methods so far designed to correct for incomplete collections by the use of a non-absorbed marker, either non-radioactive (Rose et al, 1965) or radioactive (Ogg, Pearson, and Veall, 1967), necessitate homogenizing the stool and the simplicity of the technique is lost. A wide variety of methods not involving stool collection have, therefore, been designed: eg, plasma ${ }^{47} \mathrm{Ca}$ levels after oral administration (Bhandarkar, Bluhm, MacGregor, and Nordin, 1961; Jaworski et al, 1963; Kinney et al, 1965; Avioli et al, 1965); plasma levels or urine specific activity after the simultaneous administration of different calcium isotopes intravenously and orally (Samachson, 1963; Dellipiani, Tothill, and Girdwood, 1964; De Grazia, Ivanovitch, Fellows, and Rich, 1965; Rich and Ivanovitch, 1964); wholebody counting (North, Fraser, and Belcher, 1962; Cameron, Butterfield, Veall, Rees, and Parsons, 1962; Deller et al, 1965); and external counting of the arm (Lutwak and Shapiro, 1964).

Of these methods, the determination of blood ${ }^{47} \mathrm{Ca}$ levels one, two, or three hours after an oral dose is the least demanding in terms of time and special apparatus. Bhandarkar et al (1961) claimed that it gave satisfactory results, the correlation coefficient between plasma ${ }^{47} \mathrm{Ca}$ concentration at two hours and absorption calculated from a calcium balance being $0 \cdot 78$. This was not confirmed in studies by Parsons, Butterfield, and Veall (1964) who found that twohour plasma radioactivity was too variable a measure of absorption, and may not reflect slow but effective absorption in disease states. Other workers have objected that plasma ${ }^{47} \mathrm{Ca}$ levels are misleadingly low if there is an abnormally large exchangeable calcium 
pool (Jaworski et al, 1963; Kinney et al, 1965), and as this occurs in a wide variety of disorders the method is invalid. Avioli et al (1965) have argued that this is unimportant, as within 90 minutes of an oral dose, absorbed calcium is largely restricted to the extracellular fluid compartment. The results of the present investigation suggest that this is not so, and that one-hour plasma levels can give a misleadingly low impression of absorption in malabsorption states. This is particularly true in patients with a positive calcium infusion test, in whom there is probably a larger than normal exchangeable calcium pool. On the other hand, within a relatively homogenous group of patients with a single condition (primary biliary cirrhosis) plasma levels correlated well with whole-body retention, and increased absorption after vitamin D was reflected equally well by both tests. In these patients, plasma levels, although lower before treatment in relation to retention than was the case in normal subjects, reflected changes in absorption fairly accurately.

The use of a whole-body counter obviates all the difficulties and uncertainties encountered in the use and interpretation of faecal collections of plasma samples. It is true that the whole-body counter measures calcium retention rather than true absorption, but it is unusual for the urinary ${ }^{47} \mathrm{Ca}$ excretion to be large enough to make the retention significantly smaller than absorption and retention measured by a simple whole-body counter correlated extremely well with absorption $(P<0.001)$. The few patients with an unusually high seven-day excretion of ${ }^{47} \mathrm{Ca}$ can be easily detected by measuring urinary radioactivity for the first 24 hours, and we consider it necessary to do this, as in these subjects retention can give a misleadingly low indication of true absorption. However, this was only the case in two out of 65 studies. Excretion of ${ }^{47} \mathrm{Ca}$ in the urine bore no relationship to overall ${ }^{47} \mathrm{Ca}$ absorption, but correlated fairly well with a calcium infusion test. Excretion of ${ }^{47} \mathrm{Ca}$ in the urine, therefore, depends more upon the avidity with which the body retains an absorbed dose than on the actual extent of absorption so that there is no tendency for this method either to underestimate consistently hyperabsorption or overestimate malabsorption by neglecting urinary ${ }^{47} \mathrm{Ca}$ excretion.

Absorption can therefore be studied by the simple technique of seating the patient for a few minutes in front of the whole-body counter on two occasions at an interval of one week. The range of absorption in normal subjects is wide but this has been found by other workers. Values below the normal range were encountered in four patients with primary biliary cirrhosis, three patients with cholestasis for other reasons, and one case of osteomalacia due to pan- creatic steatorrhoea, suggesting that the lower limit found was a valid figure. Of 12 patients found with retention higher than the normal range, six had been on vitamin D treatment, and one was suffering from vitamin $D$ intoxication. One was a patient with idiopathic steatorrhoea on a gluten-free diet and in clinical remission. This leaves three patients with cirrhosis and one youth with osteoporosis with an unexplained high absorption; the upper limit of normal may therefore be subject to revision, although our normal range is similar to that found with the same carrier dose by another technique (Rich and Ivanovitch, 1964). It was not possible in our limited number of patients to detect any effect of age or previous calcium intake.

In view of the wide normal range, the greatest value of this technique in routine practice and in research work might be in following response to treatment by performing successive tests in the same patients, rather than for diagnosis. Plasma levels are also probably of some use for this purpose, although their diagnostic value in a single test is very limited. The method also offers wide scope for assessing the effect of different foods on calcium absorption, and the effect of dietary treatment on calcium absorption in idiopathic steatorrhoea. The test is acceptable to both patient and doctor on an outpatient basis, and this greatly facilitates the performance of repeated studies.

\section{SUMMARY}

Three methods of studying the absorption of ${ }^{47} \mathrm{Ca}$ were compared in normal subjects, and in patients with various disorders of calcium absorption and metabolism. The results obtained by using a simple single crystal whole-body counter correlated very well with those obtained using carefully checked seven-day collections of stools and urine. The rare patient whose unusually large urinary excretion of ${ }^{47} \mathrm{Ca}$ invalidates a whole-body counter method of studying absorption can be detected by a single 24hour urine collection after the oral dose. The percentage excretion in the urine of orally administered ${ }^{47} \mathrm{Ca}$ did not correlate with the amount absorbed but the ratio of urinary to absorbed ${ }^{47} \mathrm{Ca}$ was shown to correlate with the percentage urinary excretion of an intravenously administered load of non-radioactive calcium.

Plasma levels of ${ }^{47} \mathrm{Ca}$ correlated poorly with more direct measurement of ${ }^{47} \mathrm{Ca}$ absorption. ${ }^{47} \mathrm{Ca}$ levels rose slowly during the first three hours after the oral dose in patients with poor absorption, but reached a peak at one hour in normal subjects. In addition ${ }^{47} \mathrm{Ca}$ plasma levels rose slowly in patients with obstructive jaundice even if their calcium absorption was normal, 
indicating that in some patients calcium absorption can be delayed but ultimately normal. Plasma ${ }^{47} \mathrm{Ca}$ levels gave a misleadingly low impression of absorption in patients with a positive calcium infusion test. However, in studying the effect of vitamin $\mathrm{D}$ treatment on calcium absorption, the changes in plasma ${ }^{47} \mathrm{Ca}$ levels and in ${ }^{47} \mathrm{Ca}$ wholebody retention correlated adequately, and determination of ${ }^{47} \mathrm{Ca}$ plasma levels may give a valid indication of changes in absorption in this type of study.

We wish to thank Professor Sheila Sherlock, Dr I. A. D. Bouchier, and Dr A. M. Dawson for allowing us to study patients under their care. We are grateful to $\mathrm{Mr} \mathrm{H}$. S. Williams for his encouragement, to Mrs H. Smart for carrying out the dietary surveys, and to Mrs A. P. Todd and Miss P. Middleton for advice and assistance. One of us (C.D.H.) is in receipt of a research grant from the North East Metropolitan Regional Hospital Board.

\section{REFERENCES}

Avioli, L. V., McDonald, J. E., Singer, R. A., and Henneman, P. H. (1965). A new oral isotopic test of calcium absorption. $J$. clin. Invest., 44, 128-139.

Badenoch, J., and Fourman, P. (1954). Osteomalacia in steatorrhoea. Quart. J. Med., 23, 165-176.

Barrett, J. C. (1967). Private communication.

Bhandarkar, S. D., Bluhm, M. M., MacGregor, J., and Nordin, B. E. C. (1961). An isotope test of calcium absorption. Brit. med. J., 2, 1539-1541.

Blau, M., Spencer, H., Swernov, J., Greenberg, J., and Laszlo, D. (1957). Effect of intake level on the utilization and intestinal excretion of calcium in man. J. Nutr., 61, 507-521.

Bronner, F., Harris, R. S., Maletskos, C. J., and Benda, C. E. (1956) Studies in calcium metabolism. The fate of intravenously injected radio-calcium in human beings. J. clin. Invest., 35, 78-88.

Cameron, J. S., Butterfield, W. J. H., Veall, N., Rees, J. R., and Parsons, V. (1962). Studies on intestinal calcium absorption in man using $\mathrm{Ca}^{47}$. In Medical Uses of $\mathrm{Ca}^{47}$. pp. 29-34. International Atomic energy Agency, Vienna.

Cramer, C. F. (1963). In The Transfer of Calcium and Strontium Across Biological Membranes, edited by R. H. Wasserman, pp. 75-84. Academic Press, New York and London.

DeGrazia, J. A., Ivanovich, P., Fellows, H., and Rich, C. (1965). A double isotope method for measurement of intestinal absorption of calcium in man. J. Lab. clin. Med., 66, 822-829.
- , and Rich, C. A. (1964). Studies of intestinal absorption of calcium $^{45}$ in man. Metabolism, 13, 650-660.

Deller, D. J., Worthley, B. W., and Martin, H. (1965). Measurement of calcium $^{47}$ absorption by whole-body gamma spectrometry. Aust. Ann. Med., 14, 223-231.

Dellipiani, A. W., Tothill, P., and Girdwood, R. H. (1964). The measurement of calcium absorption by a double-isotope. method. (Abstract). Int. J. appl. Radiat., 15, 497.

Fraser, R., Harrison, M., and Ibbertson, K. (1960). The rate of calcium turnover in bone. Measurement by a tracer test using stable strontium. Quart. J. Med., 29, 85-111.

Hunt, R. D., Garcia, F. G., Hegsted, D. M., and Kaplinsky, N. (1967). Vitamins $D_{2}$ and $D_{3}$ in New World primates: influence on calcium absorption. Science, 157, 943-945.

Jaworski, Z. F., Brown, E. M., Fedoruk, S., and Seitz, H. (1963). A method for the study of calcium absorption by the human gut using a standard dose of calcium labelled with calcium ${ }^{47}$. New Engl. J. Med., 269, 1103-1111.

Kehayoglou, A. K., Holdsworth, C. D., Agnew, J. E., Whelton, M. J., and Sherlock, S. (1968). Bone disease and calcium absorption in primary biliary cirrhosis. Lancet, 1, 715-719.

Kinney, V. R., Tauxe, W. N., and Dearing, W. H. (1965). Isotopic tracer studies of intestinal calcium absorption. J. Lab. clin. Med., 66, 187-203.

Lutwak, L., and Shapiro, J. R. (1964). Calcium absorption in man: based on large volume liquid scintillation counter studies. Science, 144, 1155-1157.

Nordin, B. E. C., and Fraser, R. (1956). A calcium-infusion test. I. Urinary excretion data for recognition of osteomalacia. Lancet. 1, 823-826.

North, K., Fraser, R., and Belcher, E. H. (1962). Investigation of calcium absorption in man using $\mathrm{Ca}^{47}$. In Medical Uses of $\mathrm{Ca}^{47}$, pp. 34-39. International Atomic Energy Agency, Vienna.

Ogg, G. S., Pearson, J. D., and Veall, N. (1967). The $\mathrm{Sc}^{47}$ inert marker technique as a test of calcium absorption. Radioakt. Isotope Klin. Forsch., 7, 415-418.

Parsons, V., Butterfield, W. J. H., and Veall, N. (1964). Oral ${ }^{47} \mathrm{Ca}$, a short term test of intestinal calcium absorption and balance. In Medical Uses of ${ }^{47} \mathrm{Ca}$, Second Panel Report, pp. 113-117. International Atomic Energy Agency, Vienna.

Rich, C., and Ivanovich, P. (1964). Radioisotope tests of calcium absorption. Northw. Med. (Seattle), 63, 792-796.

Rose, G. A. (1965). Experiences with the use of interrupted carmine red and continuous chromium sesquioxide marking of human faeces with reference to calcium, phosphorus, and magnesium. Gut, 5, 274-279.

—, Reed, G. W., and Smith, A. H. (1965). Isotopic method for measurement of calcium obsorption from the gastro-intestinal tract. Brit. med. J., 1, 690-692.

Samachson, J. (1963). Plasma values after oral ${ }^{45}$ calcium and ${ }^{85}$ strontium as an index of absorption. Clin. Sci., 25, 17-26.

Veall, N., and Vetter, H. (1952). An apparatus for the rapid estimation of tracer quantities of radioactive isotopes in excreta. Brit. J. Radiol., 25, 85-88. 